OPEN ACCESS

Edited by: Barbara Colombo,

Champlain College, United States

Reviewed by:

Federica Biassoni,

Catholic University of the Sacred

Heart, Italy

Jelena Kolesnikova

Riga Stradinš University, Latvia

*Correspondence:

Burkhard Peter

Burkhard-Peter@t-online.de

Specialty section

This article was submitted to

Psychology for Clinical Settings, a section of the journal

Frontiers in Psychology

Received: 13 November 2019

Accepted: 16 March 2020

Published: 21 April 2020

Citation:

Peter B and Böbel E (2020)

Significant Differences in Personality Styles of Securely and Insecurely Attached Psychotherapists: Data,

Reflections and Implications.

Front. Psychol. 11:611.

doi: 10.3389/fpsyg.2020.00611

\section{Significant Differences in Personality Styles of Securely and Insecurely Attached Psychotherapists: Data, Reflections and Implications}

\author{
Burkhard Peter* and Eva Böbel \\ Department of Psychology, Ludwig-Maximilians Universität München, Munich, Germany
}

This is a contribution to the research on the therapist variable aiming to improve effectiveness of psychotherapy. It is shown that attachment styles shape personality styles of psychotherapists in a favorable or unfavorable manner. Data on personality (PSDI) and attachment (RSQ) styles was collected from 430 psychological psychotherapists of the DACH countries using an online survey. The 88 insecurely attached psychotherapists differed significantly from their 342 securely attached colleagues in 9 of 14 personality styles: They were - even though well within normal range - more paranoid, borderline, schizoid, dependent, negativistic, selfsacrificing, avoidant, and depressive, as well as less optimistic. This corresponds to results of other researchers. Data regarding their effectiveness was not available. It is argued that a secure attachment style predispose to be a good psychotherapist. Yet, insecurely attached psychotherapists possibly compensate their adverse traits through self-therapy, continuous education, and supervision.

Keywords: psychotherapist, personality, attachment, PSDI, RSQ, therapist variable

\section{INTRODUCTION}

Treatment outcome in psychotherapy is mostly, but not exclusively, associated with factors related to the patient (e.g., severity and chronicity of the disorder), but also with therapist variables, for example, the therapist's personality and interpersonal skills (Beutler et al., 2004; Lambert, 2013). In an extensive meta-analysis, therapist effects accounted for about $5 \%$ of the variance in treatment outcome which seems small only on first sight (Baldwin and Imel, 2013). Looking closer, the therapist's influence is more profound, as he or she seems to be the crucial factor in one of the most researched and robust single predictors of treatment success, which is the therapeutic alliance (Baldwin et al., 2007; Del Re et al., 2012). The term therapeutic or working alliance refers to the collaborative partnership between client and therapist in reaching the treatment goals (Bordin, 1979; Horvath and Greenberg, 1994). It was found to account for $8 \%$ of the variance in treatment outcome in a recent meta-analysis (Flückiger et al., 2018), and therapist variability appears to be the crucial factor in alliance quality as opposed to patient variability (Del Re et al., 2012). 
However, it is not quite clear how therapists actually foster a good working alliance. A systematic review of therapists' influence on treatment outcome in psychodynamic therapies found that therapists' interpersonal functioning showed the strongest evidence for directly affecting outcome (Lingiardi et al., 2017). Likewise, Heinonen and Nissen-Lie (2019) concluded in their most recent review that more effective psychotherapists seem to be characterized by interpersonal capacities which are rooted in their personal lives and attachment history.

\section{Attachment in Therapists}

Interpersonal patterns as well as therapist attachment styles and personal caregiver history appear to be related to therapeutic alliance, thus indirectly influencing treatment outcome. Attachment styles (orientations or patterns) are assumed to be formed and fed by childhood experiences with caregivers, represented in so-called "internal working models" according to Bowlby's attachment theory (Bowlby, 1969). In adults, they are rated in interviews, e.g., by the Adult Attachment Interview, AAI (George et al., 1985), or by selfrating scales such as the Relationship Scales Questionnaire, RSQ (Griffin and Bartholomew, 1994b). While there is extensive literature on client attachment styles and their impact on the course and outcome of treatment (for an overview see Mallinckrodt and Jeong, 2015; Levy et al., 2018), the literature on therapist attachment styles is sparse. This is unsurprising because when focusing directly on the association of therapist attachment and therapeutic alliance quality in treatment, results are inconclusive, probably also due to methodological issues and the complexity of this relationship (Degnan et al., 2016; Steel et al., 2018). In a systematic review of 11 eligible treatment studies, Degnan et al. (2016) found some evidence that therapists' secure attachment was related to stronger alliances with their clients (and also to a better outcome), but also found evidence for significant interactions between therapist and client attachment patterns. Accordingly, Steel et al. (2018), in 19 papers, revealed that therapist attachment affects therapeutic relationship quality (as observed in client-rated evaluation), therapist negative countertransference, empathy, and problems in therapy. Interaction effects between client and therapist attachment style were corroborated. However, the relationship between therapist attachment style and therapeutic alliance is not straightforward, as there is also some evidence that therapists and clients with oppositional attachment styles reported more favorable alliances. Petrowski et al. (2011), e.g., reported that anxiously attached clients viewed the relationship with a more avoidant therapist as more helpful. Fuertes et al. (2019) found that therapists with higher attachment anxiety and avoidance reported more difficulties in seeing their clients in ways that benefited them, but this was not associated with the perception of the clients regarding the relationship and therapy progress. Generally, it is likely that the complexity of clients' presenting problems, coupled with the interaction between client-therapist attachment styles, influences the therapeutic alliance (Mikulincer et al., 2013; Bucci et al., 2015). Schauenburg et al. (2010), for example, reported higher attachment security of psychotherapists being associated with better alliance and outcome only in severely impaired patients. Taken together, because of their relevance for treatment outcome, therapist variables generally deserve more attention, with therapists' interpersonal functioning and attachment styles having been identified as especially noteworthy (Heinonen and Nissen-Lie, 2019).

Few studies compared therapists' attachment styles directly to population norms. 56-58\% of non-clinical adults in Western samples were found to be securely attached (BakermansKranenburg and van IJzendoorn, 2009). In therapists, the rate of secure attachment patterns seems roughly equal to this proportion: In the respective studies, about $50-70 \%$ of therapists were classified as securely attached (Dinger, 2016). Schauenburg et al. (2006) reported 45.2\%, Schauenburg et al. (2010) 61.3\%, and Dinger et al. (2009) about 50\%, Talia et al. (2018) 64\% of securely attached psychodynamic psychotherapists, as rated using the AAI. However, some studies imply that the proportion of securely attached therapists may be higher: In a sample of 50 German trainees, for example, $78 \%$ were rated to be securely attached (Taubner et al., 2014b) and 72\% of 290 licensed North American psychologists (Fleischman and Shorey, 2016).

\section{Personality in Therapists}

Therapists' personality traits in particular have scarcely been researched so far (Lingiardi et al., 2017) but are also likely to be of influence in building a good working alliance (Chapman et al., 2009; Taber et al., 2011) as well as other therapeutic skills. Although there is a substantial amount of literature on which qualities and skills therapists should present (Keenan and Rubin, 2016), there is surprisingly little research on what therapists are actually like. Regarding personality traits, most research so far has focused on how personality traits are associated with choosing a particular therapeutic approach or identifying with a particular theoretical framework (Arthur, 2001, for a review of early research). For example, some studies reported that therapists/trainees with a psychodynamic orientation presented more "Openness to Experience" (measured with the NEO Five Factor Inventory or its revised version; Costa and McCrae, 1992) compared to those with a behavioral-cognitive orientation (Poznanski and McLennan, 2003; Buckman and Barker, 2010; Taubner et al., 2014a). However, only few studies inform on therapists' personality profiles in relation to normative scores from the general population. One exception is Boswell et al. (2009) who found openness and neuroticism scores in 46 United States-American graduate student therapists in-training to be in the high range, while extraversion, agreeableness, and conscientiousness were in the average range.

In 2015, to address this question, we aimed to achieve a representative survey of therapists from the three Germanspeaking countries Germany (D), Austria (A), and Switzerland $(\mathrm{CH})$ (DACH-countries) (Peter et al., 2017). In total, 1,027 psychotherapists (average age 54 years; $71 \%$ female) anonymously completed the short version of the Personality Style and Disorder Inventory (PSDI; Kuhl and Kazén, 2009) which assesses personality styles partly based on non-pathological equivalents of classifiable personality disorders (see Table 1). Results showed that although their average personality profile was within the normal range of 40-60 T-scores, therapists scored 
significantly below the normative mean of 50 in 11 of the 14 personality styles (see Figure 1). Therapists showed especially low levels of willful/paranoid (PN), spontaneous/borderline (BL), reserved/schizoid (SZ), and ambitious/narcissistic (NA) styles, with large effect sizes. So, either therapists painted themselves in a quite positive light, or - and this is how we interpret the results - this sample of experienced clinicians (with nearly 20 years of professional practice on average) was basically free from pathological personality styles and demonstrated a personality profile which is - in our interpretation - necessary for building a good therapeutic relationship. They were able to put their personal opinions aside, show empathy and appreciation, open themselves to the emotional experience of the patient, and provide a trusting relationship. Medium effect sizes, i.e., moderate differences below the normative mean, were found in the following personality styles: Loyal/dependent (AB), critical/negativistic (NA), intuitive/schizotypal (ST), unselfish/self-sacrificing (SL), self-critical/avoidant (SU), passive/depressive (DE), and assertive/antisocial (AS). We interpreted these styles as equally indicative of the professional social skills of psychotherapists, i.e., they were neither submissive nor critical, neither excessively helpful nor too self-critical, not passive, but also not too self-assertive.

\section{Personality and Attachment - Combined Measures}

Only few studies measured both, personality and attachment. Petronzi and Masciale (2015), using the HEXACO-60
TABLE 1 | The 14 scales of the personality styles and disorders inventory (PSDI; Kuhl and Kazén, 2009).

\begin{tabular}{ll}
\hline PSDI-scale a & Example \\
\hline PN willful/paranoid & "Most people mean well" (negatively coded) \\
BL spontaneous/borderline & "My feelings often change abruptly and \\
impulsively" & "I always keep my distance to other people" \\
SZ reserved/schizoid & "The idea of being a famous personality \\
NA ambitious/narcissistic & appeals to me" \\
AB loyal/dependent & "I need a lot of love and acceptance" \\
NT critical/negativistic & "I have frequently been persecuted by bad luck" \\
ST intuitive/schizotypal & "There are supernatural force" \\
SL unselfish/self-sacrificing & "I am more concerned with other people's \\
SU self-critical/avoidant & $\begin{array}{l}\text { worries than my own needs" } \\
\text { "Criticism hurts me quicker than it does to } \\
\text { DP passive/depressive }\end{array}$ \\
AS assertive/antisocial & others" \\
HI charming/histrionic & "If people turn against me I can get them down" \\
RH optimistic/rhapsodic & "My good moods are very contagious to others" \\
ZW conscientious/compulsive & "I am an invincible optimist" \\
\hline
\end{tabular}

a DSM-5 or ICD-10 equivalents are in bold print.

(Ashton and Lee, 2009), and the Relationships Questionnaire (RQ; Bartholomew and Horowitz, 1991), examined whether people's personality and attachment styles would predict their preferences for one of three psychotherapeutic approaches.

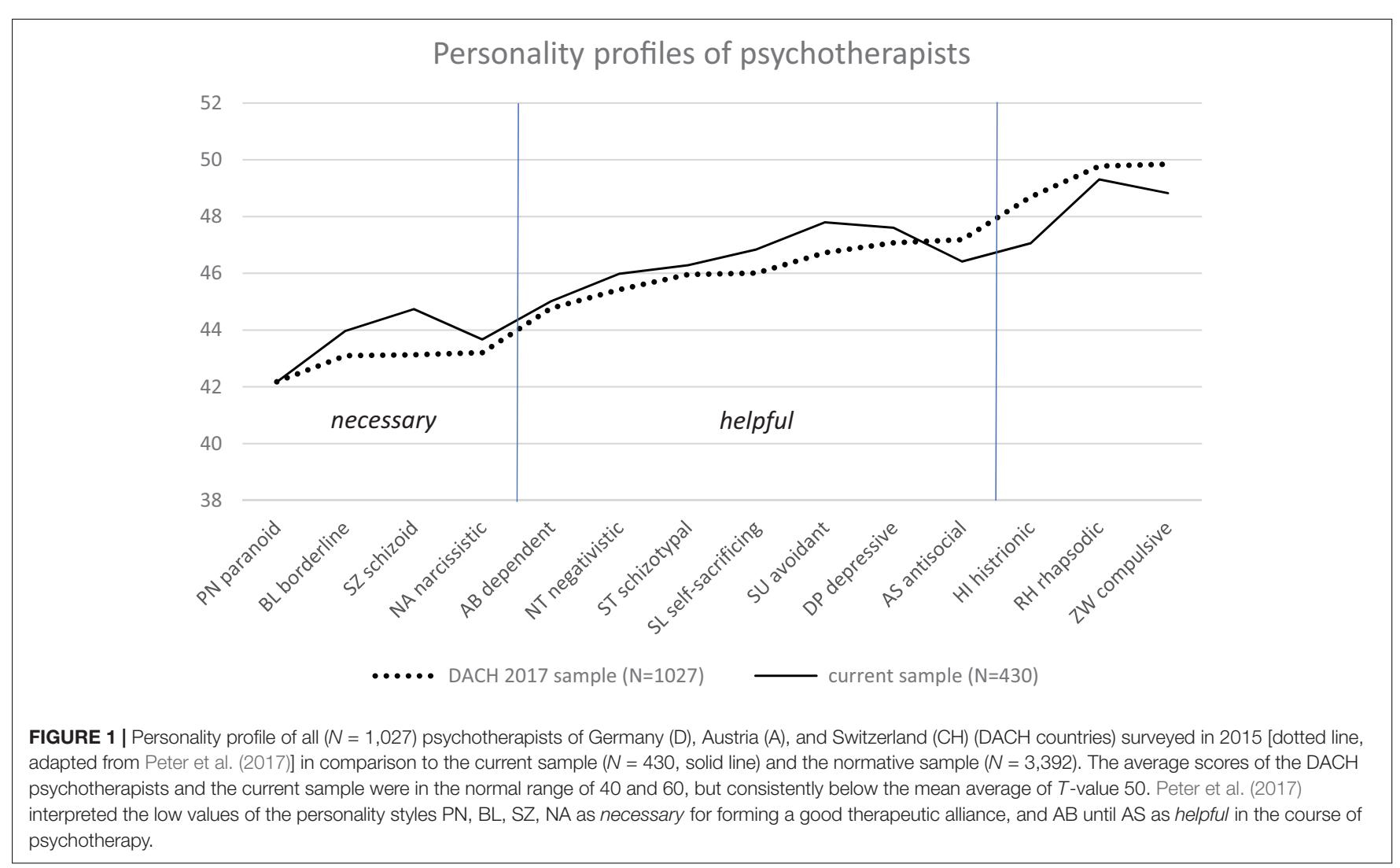


In an online sample $(N=209)$, they found that openness and secure attachment predicted a preference for psychodynamic psychotherapy, while fearful attachment predicted a preference for cognitive-behavioral psychotherapy, which is in contrast to the online survey of Fleischman and Shorey (2016) who found that psychodynamic therapists reported higher levels of attachment anxiety than cognitive-behavioral therapists.

Sherry et al. (2007), in a sample of 273 undergraduates, correlated the RSQ with 10 personality scales on the Millon Clinical Multiaxial Inventory-III (Millon et al., 1997). RSQ was able to predict seven personality styles. Insecure attachment was related to paranoid, borderline, schizoid, dependent, schizotypal, and avoidant personality styles, while secure attachment was related to the histrionic personality style. No relationships were found regarding the narcissistic, antisocial and compulsive personality styles.

In a sample of (also) 273 undergraduates (73\% female), Both and Best (2017) used the combined measures of RQ and RSQ and the NEO-PI-R (Costa and McCrae, 1992). On both measures, higher scores on secure attachment were associated with positive personality characteristics such as low neuroticism and being outgoing, while insecure patterns were associated with the opposite as well as personality facets of low trust and high depression (see Table 3). The personality factors and facets of the three insecure attachment styles can be seen in Table 3, which simultaneously gives an overview of the four-category model of attachment styles according to Bartholomew and Horowitz (1991). In summary, people with higher anxiety show higher neuroticism and lower agreeableness, and people with higher avoidance show lower levels of trust.

Finally, it should be noted that Schauenburg et al. (2006) reported considerably higher depression scores (using the BDI; Hautzinger et al., 1995) in their $45.2 \%$ insecurely attached psychodynamically oriented psychotherapists in contrast to the securely attached.

\section{Purpose of the Current Study}

Having found meaningful personality profiles in psychotherapists in 2015 (Peter et al., 2017), we were now, in 2017/18, interested in whether there would also be meaningful differences in the attachment styles of these DACH psychotherapists. With the aim of replicating and expanding our previous findings, we

TABLE 2 | Descriptive data and results of $t$-tests (by equal variances) of the two sub-samples MEG 2 and DACH 2.

\begin{tabular}{|c|c|c|c|c|c|c|c|c|c|c|}
\hline Personality styles & $\begin{array}{l}\text { Sub- } \\
\text { sample }\end{array}$ & $n$ & $\begin{array}{l}\text { Mean of } \\
T \text {-values }\end{array}$ & $S D$ & $\begin{array}{l}\text { SE of } \\
\text { mean }\end{array}$ & $T$ & $d f$ & $\begin{array}{c}p^{*}(\text { two- } \\
\text { tailed) }\end{array}$ & $\begin{array}{c}\text { Mean } \\
\text { difference } \\
\left(\bar{x}_{1}-\bar{x}_{2}\right)^{\star \star}\end{array}$ & $\begin{array}{c}\text { SE of } \\
\text { difference } \\
\left(\bar{x}_{1}-\bar{x}_{2}\right)^{* *}\end{array}$ \\
\hline \multirow[t]{2}{*}{ PN willful/paranoid } & MEG 2 & 212 & 41.41 & 8.37 & 0.58 & -1.84 & 428 & 0.067 & -1.49 & 0.815 \\
\hline & $\mathrm{DACH} 2$ & 218 & 42.90 & 8.51 & 0.58 & & & & & \\
\hline \multirow[t]{2}{*}{ BL spontaneous/borderline } & MEG 2 & 212 & 44.32 & 5.74 & 0.39 & 1.29 & 428 & 0.197 & 0.68 & 0.530 \\
\hline & $\mathrm{DACH} 2$ & 218 & 43.63 & 5.24 & 0.35 & & & & & \\
\hline \multirow[t]{2}{*}{ SZ reserved/schizoid } & MEG 2 & 212 & 44.54 & 9.53 & 0.65 & -0.43 & 428 & 0.669 & -0.39 & 0.916 \\
\hline & $\mathrm{DACH} 2$ & 218 & 44.93 & 9.47 & 0.64 & & & & & \\
\hline \multirow[t]{2}{*}{ NA ambitious/narcissistic } & MEG 2 & 212 & 44.27 & 7.59 & 0.52 & 1.63 & 428 & 0.104 & 1.19 & 0.733 \\
\hline & $\mathrm{DACH} 2$ & 218 & 43.08 & 7.61 & 0.52 & & & & & \\
\hline \multirow[t]{2}{*}{ AB loyal/dependent } & MEG 2 & 212 & 45.15 & 7.56 & 0.52 & 0.34 & 428 & 0.732 & 0.27 & 0.775 \\
\hline & $\mathrm{DACH} 2$ & 218 & 44.89 & 8.47 & 0.57 & & & & & \\
\hline \multirow[t]{2}{*}{ NT critical/negativistic } & MEG 2 & 212 & 46.42 & 7.48 & 0.51 & 1.25 & 428 & 0.214 & 0.86 & 0.692 \\
\hline & DACH 2 & 218 & 45.56 & 6.86 & 0.46 & & & & & \\
\hline \multirow[t]{2}{*}{ ST intuitive/schizotypal } & MEG 2 & 212 & 46.93 & 7.46 & 0.51 & 1.71 & 428 & 0.087 & 1.27 & 0.740 \\
\hline & $\mathrm{DACH} 2$ & 218 & 45.66 & 7.88 & 0.53 & & & & & \\
\hline \multirow[t]{2}{*}{ SL unselfish/self-sacrificing } & MEG 2 & 212 & 46.85 & 8.16 & 0.56 & 0.02 & 428 & 0.988 & 0.01 & 0.804 \\
\hline & $\mathrm{DACH} 2$ & 218 & 46.84 & 8.51 & 0.58 & & & & & \\
\hline \multirow[t]{2}{*}{ SU self-critical/avoidant } & MEG 2 & 212 & 48.73 & 7.60 & 0.52 & 2.49 & 428 & 0.013 & 1.85 & 0.741 \\
\hline & $\mathrm{DACH} 2$ & 218 & 46.89 & 7.76 & 0.53 & & & & & \\
\hline \multirow[t]{2}{*}{ DP passive/depressive } & MEG 2 & 212 & 47.71 & 6.93 & 0.48 & 0.33 & 428 & 0.745 & 0.22 & 0.679 \\
\hline & $\mathrm{DACH} 2$ & 218 & 47.49 & 7.14 & 0.48 & & & & & \\
\hline \multirow[t]{2}{*}{ AS assertive/antisocial } & MEG 2 & 212 & 46.04 & 7.64 & 0.52 & -0.98 & 428 & 0.326 & -0.75 & 0.762 \\
\hline & $\mathrm{DACH} 2$ & 218 & 46.78 & 8.14 & 0.55 & & & & & \\
\hline \multirow[t]{2}{*}{ HI charming/histrionic } & MEG 2 & 212 & 47.79 & 8.94 & 0.61 & 1.69 & 428 & 0.092 & 1.44 & 0.855 \\
\hline & $\mathrm{DACH} 2$ & 218 & 46.35 & 8.80 & 0.60 & & & & & \\
\hline \multirow[t]{2}{*}{ RH optimistic/rhapsodic } & MEG 2 & 212 & 49.96 & 8.19 & 0.56 & 1.59 & 428 & 0.113 & 1.29 & 0.807 \\
\hline & $\mathrm{DACH} 2$ & 218 & 48.68 & 8.54 & 0.58 & & & & & \\
\hline \multirow[t]{2}{*}{ ZW conscientious/compulsive } & MEG 2 & 212 & 48.56 & 7.72 & 0.53 & -0.69 & 428 & 0.488 & -0.54 & 0.780 \\
\hline & DACH 2 & 218 & 49.09 & 8.42 & 0.57 & & & & & \\
\hline
\end{tabular}

${ }^{*}$ significant if $p<0.0018 .{ }^{* *} \bar{x}_{1}=$ MEG 2, $\bar{x}_{2}=D A C H$ 2. DSM-5 or ICD-10 equivalents are in bold print. 
TABLE 3 | Four-category model of attachment styles according to Bartholomew and Horowitz (1991), the two views (positive and negative) of self and other and the dimensions of "anxiety (of separation)" and "avoidance (of closeness)."

\begin{tabular}{|c|c|c|}
\hline & $\begin{array}{l}\text { Positive view of self } \\
\text { Low anxiety }\end{array}$ & $\begin{array}{l}\text { Negative view of self } \\
\text { High anxiety }\end{array}$ \\
\hline $\begin{array}{l}\text { Positive view of other } \\
\text { Low avoidance }\end{array}$ & $\begin{array}{l}\text { RSQ secure } \\
\text { NEO factors: } \\
\text { LOW neuroticism } \\
\text { High extraversion }\end{array}$ & $\begin{array}{l}\text { RSQ insecure } \\
\text { Preoccupied } \\
\text { NEO factors: } \\
\text { High neuroticism } \\
\text { Low agreeableness } \\
\text { NEO facet: } \\
\text { High depression }\end{array}$ \\
\hline $\begin{array}{l}\text { Negative view of } \\
\text { other } \\
\text { High avoidance }\end{array}$ & $\begin{array}{l}\text { RSQ insecure } \\
\text { Dismissing } \\
\\
\text { NEO facet: } \\
\text { Low trust }\end{array}$ & $\begin{array}{l}\text { RSQ insecure } \\
\text { Fearful } \\
\text { NEO factors: } \\
\text { High neuroticism } \\
\text { Low extraversion } \\
\text { Low agreeableness } \\
\text { NEO facets: } \\
\text { High depression } \\
\text { Low trust }\end{array}$ \\
\hline
\end{tabular}

Included: the NEO-PI-R Factors and Facets of Both and Best (2017). DSM-5 or $I C D$-10 equivalents are in bold print.

again addressed this original DACH-sample and assessed both attachment and personality styles. In order to increase the number of participants, we also addressed another pool of professionals of whom we had the email addresses at hand. For both samples, (1) we expected differences in most if not all personality styles between the securely and insecurely attached psychotherapists. (2) We expected that our data would be similar to those reported by Sherry et al. (2007); Petronzi and Masciale (2015), and Both and Best (2017). And (3) we were simply curious as to whether our sample would contain more securely or insecurely attached psychotherapists, as the above referred studies differed considerably in this regard.

\section{MATERIALS AND METHODS}

\section{Sample and Recruitment Procedures}

In late 2017/early 2018, we once again contacted those approx. 4,600 previously addressed psychotherapists from the $\mathrm{DACH}$ countries via e-mail. Back in 2015, $N=1,027$ had answered, but this time only $N=267, n=189$ female, and $n=78$ male, with an average age of 57.1 ( $S D=9.39$ ) years (hereafter referred to as $\mathrm{DACH} 2$ ) responded. The reasons so few individuals replied may be as follows:

- This time we asked them to fill out the Personality Styles and Disorders Inventory (PSDI), as well as the RSQ, so the processing time doubled;

- about 200 email addresses were no longer valid;

- some respondents had already responded in 2015. (Unfortunately, we do not know how many of those from 2015 responded once more or how many responded the first time. So this is not a proper replication).
At the same time, we also emailed the same questionnaires (PSDI and RSQ) to about 3,500 additional professionals via the MEG hypnosis-3list-server (hereafter referred to as MEG 2). Of these, we obtained $N=500$ evaluable data from $n=371$ women and $n=129$ men with an average age of $52.2(\mathrm{SD}=10.2)$ years. The clinical practitioners in question were either psychological $(n=212)$ or medical $(n=47)$ psychotherapists, or were other clinical practitioners using hypnosis $(n=241$; including medical doctors without psychotherapy training, social pedagogues, etc.). For parallelization purposes, we used the data of the psychological psychotherapists only; these were $n=218$ for the DACH 2 and $n=212$ for the MEG 2 sample. As there were some recruitment differences for the two samples with regard to the context of hypnosis which are addressed in another publication by Peter and Böbel (2020), we firstly checked whether to treat both samples separately. As the comparison of the two samples' data revealed no significant differences (see Table 2) we combined them to one sample of $N=430$.

\section{Instruments}

\section{RSQ for Attachment Styles}

The German translation of the Relationship Scale Questionnaire (RSQ) was used. The RSQ is a self-rating instrument developed by Griffin and Bartholomew (1994b) which is based on attachment theory (Bowlby, 1969) and yields two underlying attachment dimensions: view of self and of other (positive and negative), and the dimensions of "anxiety (of separation)" and "avoidance (of closeness)“ (see Table 3). The RSQ consists of 30 items which are rated on a five-point Likert scale. The items ask about one's feelings in "close relationships" and attitudes concerning aspects of those relationships, such as closeness, dependency, or the feeling of being loved, somewhat explicitly as if regarding a "romantic partner." Griffin and Bartholomew (1994a) reported suitable convergent and discriminate validity of these two dimensions, and moderate to high test-retest reliability (between 0.81 and 0.84 for view of self and between 0.72 and 0.85 for view of other). Scharfe and Bartholomew (1994) reported test-retest reliabilities between 0.39 and 0.58 . Griffin and Bartholomew (1994b) reported internal consistencies ranging from 0.31 to 0.47. In a sample of Brussoni et al. (2000), internal consistencies of the RSQ scores lay at Cronbach's $\alpha=0.51,0.48,0.70$, and 0.76 (for the secure, preoccupied, dismissing, and fearful styles, respectively). The German translation was provided and published by Mestel (1994). An analysis of this German version by means of a confirmatory factor analysis Steffanowski et al. (2001) suggested four factors: anxiety (of separation), avoidance (of closeness), lack of trust and (desire for) independence. All four scales showed good internal consistency within a German speaking sample in Steffanowski et al.'s (2001) study using Cronbach's alpha ( -0.81 for anxiety, 0.77 for avoidance and lack of trust, and -0.72 for independence). Steffanowski et al. (2001) used the values of a non-clinical sample to determine appropriate cut-off values for clinical significance: 2.88 points beyond the mean of the anxiety scale and 2.75 points above the mean of the avoidance scale. Low values on both scales indicate secure attachment; high anxiety and low avoidance 
indicate an insecure-preoccupied attachment style; low anxiety and high avoidance are presumed to present an insecuredismissing attachment style. Finally, high scores on both scales (that is, anxiety and avoidance in equal measure) indicate the insecure-fearful attachment style (Table 3). To achieve enough power, we pooled the three insecure attachment styles, so in the following, we compare the two styles of secure and insecure attachment.

\section{PSDI for Personality Styles}

The original German version of the Personality Styles and Disorders Inventory (PSDI; Kuhl and Kazén, 2009) was used in its shortened version (PSDI-S) with 56 items. The PSDI is a self-assessment tool that captures the relative markedness of 14 personality styles, including 10 styles that can be considered nonpathological equivalents of the personality disorders described in DSM-IV and ICD-10 (see Table 1). The answer scales are four-level with the poles being "does not apply at all" and "fully applies." The raw values are converted into standardized $T$-values with 50 being the mean value. The normalization sample of the
PSDI-S consisted of 3,392 participants (1,763 women and 1,629 men) between the ages 12-82, who had different occupations (students, managers, regular employees, and homemakers). The PSDI-S is standardized, provides objective procedures and analyses, and mostly has satisfactory reliability (Cronbach's $\alpha=0.69-0.84$ which is slightly below Cronbach's $\alpha=0.75-$ 0.85 of the long version of the PSDI; unpublished data provided by Kazén, unpublished). The validity of the PSDI long version has been demonstrated in several studies, e.g., medium to high correlations with other inventories such as the NEO-FFI. (We refer to this issue in Table 6 and in the "Discussion" section.) According to many studies including ours (Peter and Böbel, 2020; Peter et al., 2014, Peter et al., 2017), the PSDI is a very well-suited instrument to research personality.

Please note: In order to illustrate the different personality styles, we include the names and descriptions of the respective personality disorders. For example, instead of merely referring to a personality style as "willful," we refer to it as "willful/paranoid (PN)." This is only for illustrative purposes as these additional nomenclatures are the commonly used terms in the clinical

TABLE 4 | Results of the Levene- and $t$-tests and corresponding confidence intervals of the differences between the two groups of the securely $(n=342)$ and insecurely $(n=88)$ attached psychotherapists.

\begin{tabular}{|c|c|c|c|c|c|c|c|c|}
\hline \multicolumn{9}{|c|}{ Levene test } \\
\hline Personality styles & $\begin{array}{l}\text { Variances } \\
\text { are }\end{array}$ & $\boldsymbol{F}$ & $p$ & $T$ & $d f$ & $\begin{array}{c}p^{*}(\text { two- } \\
\text { tailed) }\end{array}$ & $\begin{array}{l}\text { Mean difference } \\
\qquad\left(\bar{x}_{1}-\bar{x}_{2}\right)^{\star \star}\end{array}$ & $\begin{array}{l}\text { SE of difference } \\
\left(\bar{x}_{1}-\bar{x}_{2}\right)^{\star \star}\end{array}$ \\
\hline \multirow[t]{2}{*}{ PN willful/paranoid } & Equal & 8.59 & 0.004 & -5.92 & 428 & 0.000 & -5.763 & 0.974 \\
\hline & Unequal & & & -5.16 & 116.567 & 0.000 & -5.763 & 1.117 \\
\hline \multirow[t]{2}{*}{ BL spontaneous/borderline } & Equal & 34.53 & 0.000 & -6.81 & 428 & 0.000 & -4.266 & 0.625 \\
\hline & Unequal & & & -5.29 & 105.881 & 0.000 & -4.266 & 0.806 \\
\hline \multirow[t]{2}{*}{ SZ reserved/schizoid } & Equal & 23.89 & 0.000 & -4.14 & 428 & 0.000 & -4.610 & 1.113 \\
\hline & Unequal & & & -3.37 & 109.932 & 0.001 & -4.610 & 1.367 \\
\hline \multirow[t]{2}{*}{ NA ambitious/narcissistic } & Equal & 3.84 & 0.051 & -2.40 & 428 & 0.017 & -2.175 & 0.905 \\
\hline & Unequal & & & -2.18 & 120.926 & 0.031 & -2.175 & 0.999 \\
\hline \multirow[t]{2}{*}{ AB loyal/dependent } & Equal & 9.14 & 0.003 & -6.24 & 428 & 0.000 & -5.741 & 0.920 \\
\hline & Unequal & & & -5.34 & 114.609 & 0.000 & -5.741 & 1.074 \\
\hline \multirow[t]{2}{*}{ NT critical/negativistic } & Equal & 4.10 & 0.043 & -5.71 & 428 & 0.000 & -4.728 & 0.828 \\
\hline & Unequal & & & -5.10 & 119.156 & 0.000 & -4.728 & 0.927 \\
\hline \multirow[t]{2}{*}{ ST intuitive/schizotypal } & Equal & 10.79 & 0.001 & -1.59 & 428 & 0.113 & -1.458 & 0.918 \\
\hline & Unequal & & & -1.37 & 115.371 & 0.173 & -1.458 & 1.064 \\
\hline \multirow[t]{2}{*}{ SL unselfish/self-sacrificing } & Equal & 7.04 & 0.008 & -5.17 & 428 & 0.000 & -4.997 & 0.967 \\
\hline & Unequal & & & -4.48 & 115.789 & 0.000 & -4.997 & 1.116 \\
\hline \multirow[t]{2}{*}{ SU self-critical/avoidant } & Equal & 2.06 & 0.152 & -6.97 & 428 & 0.000 & -6.106 & 0.876 \\
\hline & Unequal & & & -6.64 & 127.501 & 0.000 & -6.106 & 0.920 \\
\hline \multirow[t]{2}{*}{ DP passive/depressive } & Equal & 7.73 & 0.006 & -8.39 & 428 & 0.000 & -6.537 & 0.780 \\
\hline & Unequal & & & -7.17 & 114.434 & 0.000 & -6.537 & 0.912 \\
\hline \multirow[t]{2}{*}{ AS assertive/antisocial } & Equal & 4.92 & 0.027 & -1.44 & 428 & 0.151 & -1.357 & 0.942 \\
\hline & Unequal & & & -1.35 & 125.388 & 0.179 & -1.357 & 1.005 \\
\hline \multirow[t]{2}{*}{ HI charming/histrionic } & Equal & 5.43 & 0.020 & 2.24 & 428 & 0.026 & 2.368 & 1.057 \\
\hline & Unequal & & & 1.96 & 116.998 & 0.052 & 2.368 & 1.207 \\
\hline \multirow[t]{2}{*}{ RH optimistic/rhapsodic } & Equal & 0.47 & 0.494 & 4.35 & 428 & 0.000 & 4.268 & 0.982 \\
\hline & Unequal & & & 4.08 & 125.662 & 0.000 & 4.268 & 1.045 \\
\hline \multirow[t]{2}{*}{ ZW conscientious/compulsive } & Equal & 0.05 & 0.820 & -0.75 & 428 & 0.452 & -0.727 & 0.966 \\
\hline & Unequal & & & -0.75 & 133.938 & 0.456 & -0.727 & 0.974 \\
\hline
\end{tabular}

* significant if $p<0.0018 .{ }^{* *} \bar{x}_{1}=$ securely attached, $\bar{x}_{2}=$ insecurely attached. DSM-5 or ICD-10 equivalents are in bold print. 
field. The mean scores of our sample, however, are well within the range established by Kuhl and Kazein (2009) as normal expressions of personality styles. As abbreviations of the styles, in this paper we use the German characters, as we did so in all other publications: The German word for "dependent" for example is "abhängig"; therefore, the abbreviation for loyal/dependent is "AB."

\section{Data Analyses}

The data collected using SoSciSurvey were loaded directly into SPSS (version 23). The confidence intervals for effect sizes were obtained with the statistical software R (Version 3.2.2). Hypotheses were tested using $t$-tests. None of the PSDI-S scales were normally distributed. However, as $t$-test is considered to be robust against violations of the assumption of normality, we chose to refrain from using non-parametric tests for two reasons: Firstly, for having more power to detect existing differences, and secondly, for having the possibility to compute confidence intervals that allow us to gauge the magnitude of these differences. Levene tests were used to assess homogeneity of variances. Because of multiple comparisons, the threshold for significance was set at $p=0.0018$ after Bonferroni correction.

\section{RESULTS}

Single sample $t$-tests were used to determine whether the $80 \%(n=342)$ securely attached psychotherapists differed from the 20\% $(n=88)$ insecurely attached ones according to personality styles, which they actually did in 9 of the 14 personality styles. The results of the Levene- and $t$-tests and corresponding $p$-values and confidence intervals of the differences between these two groups can be found in Table 4 . The mean T-scores of the personality styles of these two groups are depicted in Table 5. They as well as the means of the combined group of the $N=430$ can also be seen as personality profiles in Figure 2 together with that of the reference group of the $N=1,027$ DACH psychotherapists of 2015 (Peter et al., 2017). When comparing personality styles of securely attached $(n=342)$ to those of insecurely attached $(n=88)$ psychological psychotherapists, significant differences were found for the willful/paranoid (PN), spontaneous/borderline (BN), and reserved/schizoid (SZ) styles, as well as for the loyal/ dependent (AB), self-critical/negativistic (NA), unselfish/selfsacrificing (SL), self-critical/avoidant (SU), passive/depressive (DE), and optimistic/rhapsodic (RH) styles. No significant differences were found in the ambitious/narcissistic (NA), the ominous/schizotypal (ST), assertive/antisocial (AS) charming/histrionic (HI), and conscientious/compulsive (ZW) styles (see Table 4 for details).

\section{DISCUSSION}

The data of our 2015 survey (Peter et al., 2017) indicated that the personality styles of $N=1,027$ psychotherapists from the three German speaking countries Germany, Austria and Switzerland
TABLE 5 | Data of the two groups of securely $(n=342)$ and insecurely $(n=88)$ attached psychotherapists.

\begin{tabular}{|c|c|c|c|c|c|}
\hline $\begin{array}{l}\text { Personality } \\
\text { styles }\end{array}$ & Attachment & $n$ & $\begin{array}{l}\text { Mean of } \\
T \text {-values }\end{array}$ & $S D$ & $\begin{array}{l}\text { SE of } \\
\text { mean }\end{array}$ \\
\hline \multirow{2}{*}{$\begin{array}{l}\text { PN willful/ } \\
\text { paranoid }\end{array}$} & Secure & 342 & 40.99 & 7.70 & 0.42 \\
\hline & Unsecure & 88 & 46.75 & 9.72 & 1.04 \\
\hline \multirow{2}{*}{$\begin{array}{l}\text { BL spontaneous/ } \\
\text { borderline }\end{array}$} & Secure & 342 & 43.10 & 4.59 & 0.25 \\
\hline & Unsecure & 88 & 47.36 & 7.19 & 0.77 \\
\hline \multirow{2}{*}{$\begin{array}{l}\text { SZ reserved/ } \\
\text { schizoid }\end{array}$} & Secure & 342 & 43.80 & 8.47 & 0.46 \\
\hline & Unsecure & 88 & 48.41 & 12.08 & 1.29 \\
\hline \multirow{2}{*}{$\begin{array}{l}\text { NA ambitious/ } \\
\text { narcissistic }\end{array}$} & Secure & 342 & 43.22 & 7.28 & 0.39 \\
\hline & Unsecure & 88 & 45.40 & 8.61 & 0.92 \\
\hline \multirow{2}{*}{$\begin{array}{l}\text { AB loyal/ } \\
\text { dependent }\end{array}$} & Secure & 342 & 43.84 & 7.20 & 0.39 \\
\hline & Unsecure & 88 & 49.58 & 9.39 & 1.00 \\
\hline \multirow{2}{*}{$\begin{array}{l}\text { NT critical/ } \\
\text { negativistic }\end{array}$} & Secure & 342 & 45.02 & 6.62 & 0.36 \\
\hline & Unsecure & 88 & 49.75 & 8.03 & 0.86 \\
\hline \multirow{2}{*}{$\begin{array}{l}\text { ST intuitive/ } \\
\text { schizotypal }\end{array}$} & Secure & 342 & 45.99 & 7.21 & 0.39 \\
\hline & Unsecure & 88 & 47.44 & 9.29 & 0.99 \\
\hline \multirow{2}{*}{$\begin{array}{l}\text { SL unselfish/ } \\
\text { self-sacrificing }\end{array}$} & Secure & 342 & 45.82 & 7.61 & 0.41 \\
\hline & Unsecure & 88 & 50.82 & 9.73 & 1.04 \\
\hline \multirow{2}{*}{$\begin{array}{l}\text { SU self-critical/ } \\
\text { avoidant }\end{array}$} & Secure & 342 & 46.55 & 7.20 & 0.39 \\
\hline & Unsecure & 88 & 53.66 & 7.82 & 0.83 \\
\hline \multirow{2}{*}{$\begin{array}{l}\text { DP passive/ } \\
\text { depressive }\end{array}$} & Secure & 342 & 46.26 & 6.09 & 0.33 \\
\hline & Unsecure & 88 & 52.80 & 7.98 & 0.85 \\
\hline \multirow{2}{*}{$\begin{array}{l}\text { AS assertive/ } \\
\text { antisocial }\end{array}$} & Secure & 342 & 46.14 & 7.70 & 0.42 \\
\hline & Unsecure & 88 & 47.50 & 8.58 & 0.91 \\
\hline \multirow{2}{*}{$\begin{array}{l}\text { HI charming/ } \\
\text { histrionic }\end{array}$} & Secure & 342 & 47.55 & 8.37 & 0.45 \\
\hline & Unsecure & 88 & 45.18 & 10.50 & 1.12 \\
\hline \multirow{2}{*}{$\begin{array}{l}\mathrm{RH} \text { optimistic/ } \\
\text { rhapsodic }\end{array}$} & Secure & 342 & 50.18 & 8.03 & 0.43 \\
\hline & Unsecure & 88 & 45.91 & 8.92 & 0.95 \\
\hline \multirow{2}{*}{$\begin{array}{l}\text { ZW conscientious/ } \\
\text { compulsive }\end{array}$} & Secure & 342 & 48.68 & 8.06 & 0.44 \\
\hline & Unsecure & 88 & 49.41 & 8.17 & 0.87 \\
\hline
\end{tabular}

DSM-5 or ICD-10 equivalents are in bold print.

(DACH countries) differed from the norm (i.e., T-scores of 50 in Figure 1). In 2015 we had divided the personality styles into three groups according to the effect sizes of the differences. This resulted in reference data with which we can compare the data of the present sample of 2017/18. This time, in addition to the personality styles, we also asked for attachment styles from 430 psychological psychotherapist of the same DACH countries. We again used the PSDI by Kuhl and Kazén (2009) and added the RSQ by Griffin and Bartholomew (1994b).

Looking at Figure 2, it is obvious that the profile of the $n=342$ securely attached psychotherapists of the present study (drawn through double line) - as compared with the insecurely attached (bold interrupted line) - is almost identical to the profile of the $N=1,027$ DACH psychotherapists (dotted line) of 2015. As we had not considered attachment in 2015, an unknown number of insecurely attached psychotherapists was included in the whole sample. Judging by the minor deviations from the profile of the now $n=342$ securely attached psychotherapists, these insecurely attached psychotherapists must not have been high in number. The $n=88$ insecurely attached psychotherapists of the present sample also comprise only $20 \%$ of the total $N=430$. This is similar to the rate of the German study by Taubner et al. (2014b) and that of the North American study by Fleischman and Shorey (2016), 
TABLE 6 | Correlations between NEO-FFI and PSDI values (Kuhl and Kazén, 2009).

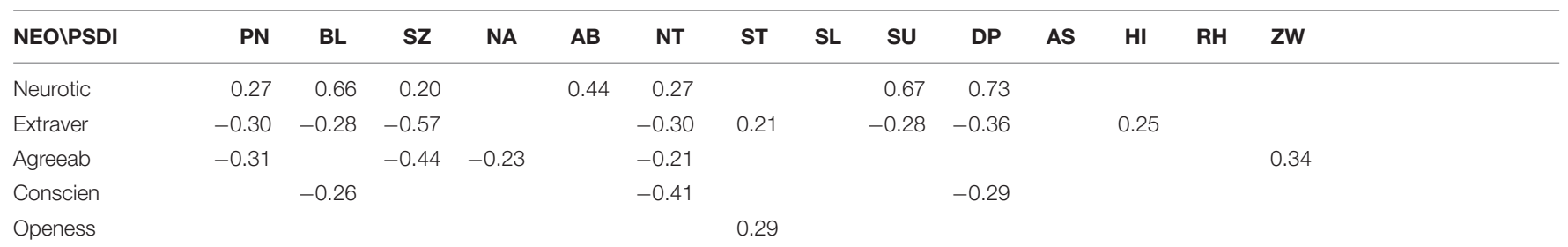

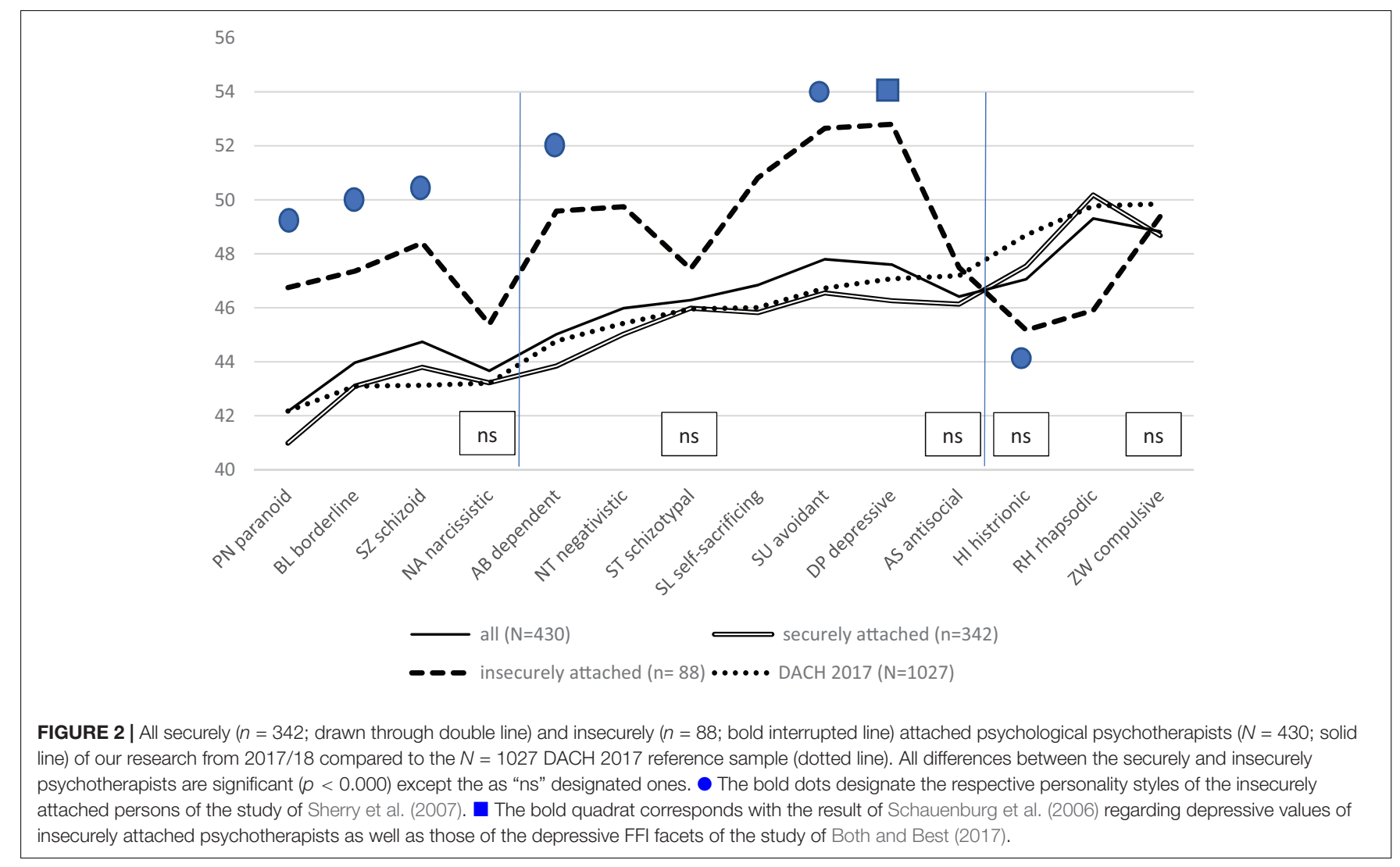

while dissimilar to the studies by the Heidelberg group (Dinger et al., 2009; Schauenburg et al., 2010).

The 20\% insecurely attached psychological psychotherapists in the present sample (bold interrupted line) show a personality profile which differs significantly and adversely from that of the $80 \%$ securely attached in 9 of 14 styles. In the 2015 data, Peter et al. (2017) considered the first group of four personality styles (PN, BL, SZ, NA; see Figure 1) as necessary for building a good therapeutic relationship. In three of these four styles - willful/paranoid (PN), spontaneous/borderline (BL), and reserved/schizoid (SZ) - the insecurely attached individuals of the present sample scored significantly worse than their securely attached counterparts - even while they were still within the normal range between 40 and 60 and below the normative mean of $50 \mathrm{~T}$-scores. Of the seven styles of the second group, which in 2015 we considered as helpful in the course of psychotherapy, the insecurely attached of the present sample likewise differed significantly in 5 of them, showing much higher, i.e., worse, values in the styles loyal/dependent $(\mathrm{AB})$ and critical/negativistic
(NT) - almost at the level of 50 -, and in unselfish/self-sacrificing (SL), self-critical/avoidant (SU), and passive/depressive (DE) above the level of $50 \mathrm{~T}$-scores. In the third group, which showed no differences to the norm in 2015, the insecurely attached participants of the present sample were significantly not as optimistic/rhapsodic (RH) as the securely attached, and, even though not significantly, they were not as charming/histrionic (HI) as their securely attached counterparts (see Figure 2).

It is intriguing that the results by Sherry et al. (2007) in insecurely attached persons are very similar to ours, as six personality styles of theirs match very well with five of ours, namely the styles paranoid, borderline, schizoid, dependent, and avoidant (cf the bold dots in Figure 2). The exception is schizotypal because we didn't find any difference regarding this style; another exception are Sherry et al.'s values in the histrionic style for the insecurely attached which is similar to ours. However, they did not reach the required level of significance (Table 4 and Figure 2). Sherry et al.'s (2007) personality data was collected using Millon's Inventory and is 
therefore not directly comparable to our data surveyed using the PSDI, although a high correspondence of both results is apparent. This is also true for the results by Both and Best (2017) who, using the NEO-PI-R, found low neuroticism and high extraversion for the securely attached, versus high neuroticism, low extraversion, and low agreeableness for the insecurely attached, as well as high depression and low trust (see Table 3). This corresponds very well with our PSDI values of the paranoid $(\mathrm{PN})$, borderline $(\mathrm{BL})$, schizoid $(\mathrm{SZ})$, dependent $(\mathrm{AB})$, negativistic (NT), avoidant $(\mathrm{Su})$, and depressive (DP) personality styles, as Kuhl and Kazén (2009) found meaningfully significant correlations between these styles and the factors neuroticism, extraversion, and agreeableness of the NEO-FFI (see Table 6, which we placed closely above Figure 2, in order to make the correspondence visible). Additionally, the results by Schauenburg et al. (2006) correspond with ours, as our insecurely attached individuals differed most from the securely attached in the passive/depressive (DP) style (see the bold quadrat in Figure 2). Moreover, it is of note that the results by Sherry et al. (2007) as well as those by Both and Best were drawn from young undergraduates, while the results by Schauenburg et al. (2006) as well as our own refer to older professional psychotherapists, meaning that the correlation of personality with attachment styles is probably a stable one.

\section{CONCLUSION}

Successful outcomes in psychotherapy depend on many factors such as technical interventions, patients' pathology and characteristics, and therapeutic relationship or alliance, respectively. The therapeutic relationship has been the topic of extensive theoretical and practical elaborations since the beginnings of psychotherapy in 1775 (Peter and Revenstorf, 2018) and have received more attention in psychotherapy research at least since the end of the last century (Horvath and Symonds, 1991). Therapeutic relationship and alliance are highly dependent on the psychotherapist. As early as 1986, Luborsky et al. (1986) stated, that "variations in success rate typically have more to do with the therapist than with the type of treatment." This statement on the therapist variable has been confirmed by others (Baldwin et al., 2007; Dinger et al., 2008; Zuroff et al., 2010; Norcross and Lambert, 2018; Norcross and Wampold, 2018). Parts of the therapist variable are concerned with personality and attachment styles of therapists. Therapist's attachment status is obviously highly associated with his/her ability to attune to patients and this influences the therapeutic process considerably (Talia et al., 2018). Also, according to Lingiardi et al. (2017), there is primary evidence that therapists' attachment styles, their interpersonal history with caregivers, and their self-concept influences treatment outcome. Peter et al. (2017) published the first study which correlated therapists' personality styles with a public norm and suggested that special personality styles of the therapists' may be necessary and others helpful for forming a good therapeutic alliance. In the present study we correlated personality and attachment styles and confirmed the results by
Both and Best (2017), Schauenburg et al. (2006), and Sherry et al. (2007) who also found significant differences between securely and insecurely attached psychotherapists. From this, one could infer that personality and attachment styles are crucial factors for being or becoming a good psychotherapist if one considers them to be strong moderators for therapeutic alliance with the latter being a strong factor for therapeutic outcome (Baldwin et al., 2007). However, this would be a kind of assertion which has not yet been proven. Such an assertion might be overly generalized as it is not substantiated by our study. So we must be careful to attribute attachment such a decisive role for psychotherapeutic practice. As long as we lack data attachment can be only considered a moderator variable.

\section{LIMITATIONS AND IMPLICATIONS}

There are many limitations of our study which we have already discussed extensively in Peter et al. (2017). What is more, because all our data was collected from German speaking psychotherapists of the DACH countries a cultural bias must be presumed. The transfer of applying the results and implications to other sociocultural contexts is therefore problematic. First of all, however, we had no chance in our anonymous online survey to receive data about outcome. This we consider a main limitation to the implications of our study. Yet, also Sherry et al. (2007) as well as Both and Best by examining young undergraduates (of 22,15 and 20,54 years in the mean) did not touch upon this outcome issue, and even Schauenburg et al., 2006 who used psychotherapists (mean 37,4 years) did not report on outcome. In a later study, however, Schauenburg et al. (2010) found no general main effects of therapists' attachment styles to predict alliance and outcome with the exception of more severely impaired patients, where higher attachment security of the therapist was associated with both better alliance and outcome. So, we should be careful regarding our study's implications on the personal and professional quality of our psychotherapists.

It may be that there are some personality styles that predispose for wishing to become a psychotherapist (Prade et al., 2014) and then to be a good psychotherapist. Others may be unfavorable. Insecure attachment styles obviously correlate with personality styles which are - according to the results of Peter et al. (2017) not favorable to form a good therapeutic relationship. Yet, are they indicative of being a bad psychotherapist? Many educational factors in the course of the training and then being a psychotherapist may compensate for possible adverse personality and attachment styles (Rizq and Target, 2010). The extensive selfanalysis of the psychoanalysts and the profound self-explorations of psychodynamic psychotherapists are examples of these kinds of compensatory measures. The relevance of the alliance factor is acknowledged in almost all of today's psychotherapy approaches (Fiedler, 2018). Large parts of the education in client-centered therapy and Ericksonian hypnotherapy for example were and are devoted to verbal and non-verbal skills to get in contact with a patient, to establish a good therapeutic relationship and to use this "rapport" for the benefit of the patients (Revenstorf and Peter, 2015). Personal therapy is used by 
many psychotherapists of all orientations, and supervision and continuous education in the course of psychotherapeutic practice is a matter-of-course requirement (Bike et al., 2009; Orlinsky et al., 2011). Just one pointer toward this educational hypothesis would be our sample's mean age of 57.1 years, meaning that the $20 \%$ of the insecurely attached have had enough time and options to readapt their unfavorable styles to the needs of their profession. So, training, continuous education, self-exploration, experience, and supervision may compensate for therapists' attachment deficits and may serve as an acquired resource for therapeutic effectiveness. It has been shown that attachment representations can be improved by psychotherapy (Taylor et al., 2015; Buchheim et al., 2017). Therefore, future studies might be able to demonstrate whether it is possible, in the process of psychotherapy education, to change an insecure attachment style essentially so that the respective personality styles match with that of securely attached psychotherapists. This, then probably, would result in a kind of "earned security" (Pearson et al., 1994). If not, would it be possible to show that, at least, the "rapport" behavior could be changed in order to enable psychotherapists to establish and maintain a good therapeutic alliance. Applying PSDI and RSQ measurements at the beginning and the end of psychotherapy education curricula could help to answer those questions and to provide replication data for our study.

\section{DATA AVAILABILITY STATEMENT}

The raw data supporting the conclusions of this article will be made available by the authors, without undue reservation, to any qualified researcher.

\section{REFERENCES}

Arthur, A. R. (2001). Personality, epistemology and psychotherapists' choice of theoretical model: a review and analysis. Eur. J. Psychother. Couns. Health 4, 45-64. doi: 10.1080/13642530110040082

Ashton, M. C., and Lee, K. (2009). The HEXACO-60: a short measure of the major dimensions of personality. J. Pers. Asess. 91, 340-345. doi: 10.1080/ 00223890902935878

Bakermans-Kranenburg, M. J., and van IJzendoorn, M. H. (2009). No reliable gender differences in attachment across the lifespan. Behav. Brain Sci. 32, 22-23. doi: 10.1017/s0140525x0900003x

Baldwin, S., Wampold, B., and Imel, Z. (2007). Untangeling the alliance-outcome correlation: exploring the relative importance of therapist and patient variability in the alliance. J. Consult. Clin. Psychol. 75, 842-852. doi: 10.1037/0022-006X. 75.6 .842

Baldwin, S. A., and Imel, Z. E. (2013). "Therapists effects," in Bergin and Garfield's Handbook of Psychotherapy and Behavior Change, 6 Edn, ed. M. J. Lambert (New York, NY: Wiley), 258-297.

Bartholomew, K., and Horowitz, L. M. (1991). Attachment styles among young adults: a test of a four-category model. J. Pers. Soc. Psychol. 61, 226-244. doi: 10.1037/0022-3514.61.2.226

Beutler, L. E., Malik, M., Alimohamed, S., Harwood, T. M., Talebi, H., Nobel, S., et al. (2004). "Therapist variables," in Bergin and Garfield's Handbook of Psychotherapy and Behavior Change, 5 Edn, ed. M. Lambert (New York, NY: Wiley), 227-306.

\section{ETHICS STATEMENT}

In accordance with the Declaration of Helsinki and local legislation, no formal institutional approval was sought because of the very nature of the study (online survey targeting adults and using a transparent, non-offending personality questionnaire): Psychotherapists were contacted by e-mail addresses and informed openly about the aim and purpose of the study. They filled in the questionnaire anonymously and received no compensation for participation. Therefore, no additional written consent was sought other than the consent expressed by participating.

\section{AUTHOR CONTRIBUTIONS}

BP conceptualized the study, organized the data collection and study setup, and wrote the manuscript. EB performed the statistical analysis and contributed substantially to writing the method and results section.

\section{FUNDING}

Funds received from MEG-Stiftung for open access publication fees.

\section{ACKNOWLEDGMENTS}

The authors are very grateful to Maria Hagl for assisting with the first draft of the introduction, and to Maren Jordans for her final carefully editing the English text.

Bike, D. H., Norcross, J. C., and Schatz, D. M. (2009). Processes and outcomes of psychotherapists' personal therapy: replication and extension 20 years later. Psychother. Theory Res. Pract. Train. 46, 19-31. doi: 10.1037/a001 5139

Bordin, E. S. (1979). The generalizability of the psychoanalytic concept of the working alliance. Psychother. Theory Res. Pract. 16, 252-260. doi: 10.1037/ h0085885

Boswell, J. F., Castonguay, L. G., and Pincus, A. L. (2009). Trainee theoretical orientation: profiles and potential predictors. J. Psychother. Integr. 19, 291-312. doi: $10.1037 / \mathrm{a} 0017068$

Both, L. E., and Best, L. A. (2017). A comparison of two attachment measures in relation to personality factors and facets. Pers. Individ. Dif. 112, 1-5. doi: 10.1016/j.paid.2017.02.040

Bowlby, J. (1969). Attachment and Loss: Attachment, Vol. 1. New York, NY: Basic Books.

Brussoni, M. J., Jang, K. L., Livesley, W. J., and Macbeth, T. M. (2000). Genetic and environmental influences on adult attachment styles. Pers. Relat. 7, 283-289. doi: 10.1016/j.smrv.2014.03.002

Bucci, S., Seymour-Hyde, A., Harris, A., and Berry, K. (2015). Client and therapist attachment styles and working alliance. Clin. Psychol. Psychother. 23, 155-165. doi: 10.1002/cpp.1944

Buchheim, A., Hörz-Sagstetter, S., Doering, S., Rentrop, M., Schuster, P., Buchheim, P., et al. (2017). Change of unresolved attachment in Borderline Personality Disorder: RCT study of transference-focused psychotherapy. Psychother. Psychosom. 86, 314-316. doi: 10.1159/000460257 
Buckman, J. R., and Barker, C. (2010). Therapeutic orientation preferences in trainee clinical psychologists: Personality or training? Psychother. Res. 20, 247258. doi: 10.1080/10503300903352693

Chapman, B. P., Talbot, N., Tatman, A. W., and Britton, P. C. (2009). Personality traits and the working alliance in psychotherapy trainees: An organizing role for the Five Factor Model? J. Soc. Clin. Psychol. 28, 577-596. doi: 10.1521/jscp. 2009.28.5.577

Costa, P. T., and McCrae, R. R. (1992). NEO Personality Inventory-Revised (NEO$P I-R$ ) and NEO Five-Factory Inventory (NEO-FFI) Professional Manual. Odessa, FL: Psychological Assessment Resources.

Degnan, A., Seymour-Hyde, A., Harris, A., and Berry, K. (2016). The role of therapist attachment in alliance and outcome: a systematic literature review. Clin. Psychol. Psychother. 23, 47-65. doi: 10.1002/cpp.1937

Del Re, A. C., Flückiger, C., Horvath, A. O., Symonds, D., and Wampold, B. E. (2012). Therapist effects in the therapeutic alliance-outcome relationship: a restricted-maximum likelihood meta-analysis. Clin. Psychol. Rev. 32, 642-649. doi: 10.1016/j.cpr.2012.07.002

Dinger, U. (2016). Ist die Therapiebeziehung eine Bindungsbeziehung? Einfluss innerer Arbeitsmodelle von Bindung auf den Therapieprozess. [Is therapistpatient relationship an attachment relationship? Influence of internal working models of attachment on therapy process]. Psychother. Dialog 17, 32-35. doi: 10.1055/s-0042-109309

Dinger, U., Strack, M., Leichsenring, F., Wilmers, F., and Schauenburg, H. (2008). Therapist effects on outcome and alliance in inpatient psychotherapy. J. Clin. Psychol. 64, 344-354. doi: 10.1002/jclp.20443

Dinger, U., Strack, M., Sachsse, T., and Schauenburg, H. (2009). Therapists attachment, patients' interpersonal problems and alliance development over time in inpatient psychotherapy. Psychother. Theory Res. Pract. Train. 46, 277-290.

Fiedler, P. (ed.) (2018). Varianten psychotherapeutischer Beziehung. Transdiagnostische Befunde, Konzepte Perspektiven [Variants of psychotherapeutic relationship. Transdiagnostic findings, concepts, perspectives]. Lengerich: Pabst.

Fleischman, S., and Shorey, H. S. (2016). The relationships between adult attachment, theoretical orientation, and therapist-reported alliance quality among licensed psychologists. Psychother. Res. 26, 95-105. doi: 10.1080/ 10503307.2014.947390

Flückiger, C., Del Re, A. C., Wampold, B. E., and Horvath, A. O. (2018). The alliance in adult psychotherapy: a meta-analytic synthesis. Psychotherapy 55, 316-340. doi: 10.1037/pst0000172

Fuertes, J. N., Moore, M., and Ganley, J. (2019). Therapists' and clients' ratings of real relationship, attachment, therapist self-disclosure, and treatment progress. Psychother. Res. 29, 594-606. doi: 10.1080/10503307.2018.1425929

George, C., Kaplan, N., and Main, M. (1985). The Adult Attachment Interview. Berkeley, CA: University of California.

Griffin, D., and Bartholomew, K. (1994a). Models of the self and other Fundamental dimensions underlying measures of adult attachment. J. Pers. Soc. Psychol. 67, 430-435

Griffin, D., and Bartholomew, K. (1994b). "The metaphysics of measurement: the case of adult attachment," in Advances in Personal Relationships, Vol. Vol. 5, eds K. Bartholomew and D. Perlman (London: Jessica Kingsley), 17-52.

Hautzinger, M., Bailer, M., Worall, K., and Keller, F. (1995). Beck-DepressionsInventar - Deutsche Version. Weinheim: Beltz Testverlag.

Heinonen, E., and Nissen-Lie, H. A. (2019). The professional and personal characteristics of effective psychotherapists: a systematic review. Psychother. Res. [Epub ahead of print].

Horvath, A. O., and Greenberg, L. (1994). The Working Alliance: Theory, Research, and Practice. Oxford: John Wiley \& Sons.

Horvath, A. O., and Symonds, B. D. (1991). Relation between working alliance and outcome in psychotherapy: a meta-analysis. J. Couns. Psychol. 38, 139-149. doi: 10.1037/0022-0167.38.2.139

Keenan, K., and Rubin, S. (2016). "The good therapist: Evidence regarding the therapist's contribution to psychotherapy," in Humanistic Psychotherapies: Handbook of Research and Practice, eds D. J. Cain, K. Keenan, S. Rubin, D. J. Cain, K. Keenan, and S. Rubin (Washington, DC: American Psychological Association), 421-454. doi: 10.1037/14775-014

Kuhl, J., and Kazén, M. (2009). Persönlichkeits-Stil- und Störungs-Inventar (PSSI). Manual [Personality Style and Disorder inventory (PSDI). Göttingen: Hogrefe.
Lambert, M. (2013). "The efficacy and effectiveness of psychotherapy," in Bergin and Garfield's Handbook of Psychotherapy and Behavior Change, 6 Edn, ed. M. Lambert (New York, NY: Wiley), 169-218.

Levy, K. N., Kivity, Y., Johnson, B. N., and Gooch, C. V. (2018). Adult attachment as a predictor and moderator of psychotherapy outcome: a meta-analysis. J. Clin. Psychol. 74, 1996-2013. doi: 10.1002/jclp.22685

Lingiardi, V., Muzi, L., Tanzilli, A., and Carone, N. (2017). Do therapists'subjective variables impact on psychodynamic psychotherapy outcomes? A systematic literature review. Clin. Psychol. Psychother. 25, 85-101. doi: 10.1002/cpp.2131

Luborsky, L., Crits-Christoph, P., McLellan, A., Woody, G., Piper, W., Liberman, B., et al. (1986). Do therapists vary much in their success? Findings from four outcome studies. Am. J. Orthopsychiatry 56, 501-521. doi: 10.1111/j.1939-0025. 1986.tb03483.x

Mallinckrodt, B., and Jeong, J. (2015). Meta-analysis of client attachment to therapist: associations with working alliance and client pretherapy attachment. Psychotherapy 52, 134-139. doi: 10.1037/a0036890

Mestel, R. (1994). Deutsche Übersetzung des RSQ. Grönenbach: Klinik für Psychosomatische Medizin.

Mikulincer, M., Shaver, P. R., and Berant, E. (2013). An attachment perspective on therapeutic processes and outcomes. J. Pers. 81, 605-616.

Millon, T., Davis, R., and Millon, C. (1997). MCMI-III, 2 Edn. Minneapolis, MN: NCS.

Norcross, J. C., and Lambert, M. J. (2018). Psychotherapy relationships that work III. Psychotherapy 59, 303-315. doi: 10.1037/pst0000193

Norcross, J. C., and Wampold, B. E. (2018). A new therapy for each patient: Evidence-based relationships and responsiveness. J. Clin. Psychol. 74, 18891906. doi: $10.1002 /$ jclp. 22678

Orlinsky, D. E., Schofield, M. J., Schroder, T., and Kazantzis, N. (2011). Utilization of personal therapy by psychotherapists: a practice-friendly review and a new study. J. Clin. Psychol. 67, 828-842. doi: 10.1002/jclp.2 0821

Pearson, J., Cohn, D., Cowan, P., and Cowan, C. (1994). Earned- and continuoussecurity in adult attachment: relation to depressive symptomatology and parenting style. Dev. Psychopathol. 6, 359-373.

Peter, B., and Böbel, E. (2020). Does the homo hypnoticus exist? Personality styles of people interested in hypnosis. Int. J. Clin. Exp. Hypn. (in press).

Peter, B., Böbel, E., Hagl, M., Richter, M., and Kazén, M. (2017). Personality styles of German-speaking psychotherapists differ from a norm, and male psychotherapists differ from their female colleagues. Front. Psychol. 8:840. (in press). doi: 10.3389/fpsyg.2017.00840

Peter, B., and Revenstorf, D. (2018). "Rapport und therapeutische Beziehung in der Hypnotherapie [Rapport and therapeutic alliance in hypnotherapy]," in Varianten psychotherapeutischer Beziehung. Transdiagnostische Befunde, Konzepte, Perspektiven, ed. P. Fiedler (Lengerich: Pabst), 119-142.

Peter, B., Vogel, S., Prade, T., Geiger, E., Mohl, J., and Piesbergen, C. (2014). Hypnotizability, personality style and attachment. An exploratory study. Part 1: general results. Am. J. Clin. Hypn. 57, 13-40. doi: 10.1080/00029157.2014. 906152

Petronzi, G. J., and Masciale, J. N. (2015). Using personality traits and attachment styles to predict people's preference of psychotherapeutic orientation. Couns. Psychother. Res. 15, 298-308. doi: 10.1002/capr.12036

Petrowski, K., Nowacki, K., Pokorny, D., and Buchheim, A. (2011). Matching the patient to the therapist. The roles of the attachment status and the helping alliance. [Passung zwischen Patient und Therapeut: Die Rolle des Bindungsstatus' und der therapeutischen Arbeitsbeziehung]. J. Nerv. Ment. Dis. 199, 839-844. doi: 10.1097/NMD.0b013e318 2349cce

Poznanski, J. J., and McLennan, J. (2003). Becoming a psychologist with a particular theoretical orientation to counseling practice. Aust. Psychol. 38, 223-226. doi: $10.1080 / 00050060310001707247$

Prade, T., Geiger, E., and Peter, B. (2014). Persönlichkeitsstile und Studienbzw. Berufswünsche jugendlicher Schüler und Schülerinnen, die sich für Hypnose interessieren. (Personality and career aspiration of adolescent students interested in hypnosis). Hypnose ZHH 9, 45-67.

Revenstorf, D., and Peter, B. (eds) (2015). Hypnose in Psychotherapie, Psychosomatik und Medizin. Manual für die Praxis [Hypnosis in Psychotherapy, Psycosomatic, and Medicine], 3 Edn. Heidelberg: Springer. 
Rizq, R., and Target, M. (2010). 'If that's what I need, it could be what someone else needs.' Exploring the role of attachment and reflective function in counselling psychologists' accounts of how they use personal therapy in clinical practice: a mixed methods study. Br. J. Guid. Couns. 38, 459-481. doi: 10.1080/03069885. 2010.503699

Scharfe, E., and Bartholomew, K. (1994). Reliability and stability of adult attachment patterns. Pers. Relat. 1, 23-43. doi: 10.1111/j.1475-6811.1994. tb00053.x

Schauenburg, H., Buchheim, A., Beckh, K., Nolte, T., Brenk-Franz, K., Leichsenring, F., et al. (2010). The influence of psychodynamically oriented therapists' attachment representations on outcome and alliance in inpatient psychotherapy. Psychother. Res. 20, 193-202. doi: 10.1080/1050330090320 4043

Schauenburg, H., Dinger, U., and Buchheim, A. (2006). Bindungsmuster von Psychotherapeuten. [Attachment patterns in psychotherapists]. Z. Psychosom. Med. Psychother. 52, 358-372. doi: 10.13109/zptm.2006.52.4.358

Sherry, A., Lyddon, W. J., and Henson, R. K. (2007). Adult attachment and developmental personality styles: an empirical study. J. Couns. Dev. 85, $337-$ 348. doi: 10.1002/j.1556-6678.2007.tb00482.x

Steel, C., Macdonald, J., and Schroder, T. (2018). A systematic review of the effect of therapists' internalized models of relationships on the quality of the therapeutic relationship. J. Clin. Psychol. 74, 5-42. doi: 10.1002/jclp.2 2484

Steffanowski, A., Oppl, M., Meyerberg, J., Schmidt, W. W., Wittmann, W. W., and Nübling, R. (2001). "Psychometrische Überprüfung einer deutschsprachigen Version des Relationship Scales Questionaire (RSQ)," in Störungsspezifische Therapieansätze - Konzepte und Ergebnisse, ed. M. Bassler (Gießen: Psychosozial).

Taber, B. J., Leibert, T. W., and Agaskar, V. R. (2011). Relationships among clienttherapist personality congruence, working alliance, and therapeutic outcome. Psychotherapy 48, 376-380. doi: 10.1037/a0022066

Talia, A., Muzi, L., Lingiardi, V., and Taubner, S. (2018). How to be a secure base: therapists' attachment representations and their link to attunement in psychotherapy. Attach. Hum. Dev. 22, 189-206. doi: 10.1080/14616734.2018. 1534247

Taubner, S., Munder, T., Möller, H., Hanke, W., and Klasen, J. (2014a). Selbstselektionsprozesse bei der Wahl des therapeutischen Ausbildungsverfahrens: unterschiede in therapeutischen Haltungen, Persönlichkeitseigenschaften und dem Mentalisierungsinteresse. [Selfselection processes in the choice of the therapeutic training approach: differences in therapeutic attitudes, personality traits, and attributional complexity]. Psychother. Psychosom. Med. Psychol. 64, 214-223. doi: 10.1055/s-0033-1358720

Taubner, S., Ulrich-Manns, S., Klasen, J., Curth, C., Möller, H., and Wolter, S. (2014b). Innere Arbeitsmodelle von Bindung und aversive Kindheitserfahrungen bei Psychotherapeuten in Ausbildung. [Inner working models of attachment and aversive childhood experiences of psychotherapists in training]. Psychother. Forum 19, 2-12. doi: 10.1007/s00729-014-0005-4

Taylor, P., Rietzschel, J., Danquah, A., and Berry, K. (2015). Changes in attachment representations during psychological therapy. Psychother. Res. 25, 222-238. doi: 10.1080/10503307.2014.886791

Zuroff, D. C., Kelly, A. C., Leybman, M. J., Blatt, S. J., and Wampold, B. E. (2010). Between-therapist and within-therapist differences in the quality of the therapeutic relationship: effects on maladjustment and self-critical perfectionism. J. Clin. Psychol. 66, 681-697. doi: 10.1002/jclp.20683

Conflict of Interest: The authors declare that the research was conducted in the absence of any commercial or financial relationships that could be construed as a potential conflict of interest.

Copyright (c) 2020 Peter and Böbel. This is an open-access article distributed under the terms of the Creative Commons Attribution License (CC BY). The use, distribution or reproduction in other forums is permitted, provided the original author(s) and the copyright owner(s) are credited and that the original publication in this journal is cited, in accordance with accepted academic practice. No use, distribution or reproduction is permitted which does not comply with these terms. 